\title{
Die nationalpolitische Bedeutung der Germanistik im 19. Jahrhundert: Der Indogermanenmythos als Trieb- kraft des deutschen Nationalismus
}

Die Nationwerdung setzte sich im 18. und 19. Jahrhundert in Europa und auch in Deutschland mit historischer Notwendigkeit durch. Bei der Entstehung eines deutschen nationalen SelbstbewuBtseins hat die deutsche Germanistik eine bedeutende Rolle gespielt. Deutsche Philologen edierten deutsche historische Texte, sammelten Wörter in einen Thesaurus und wendeten die Blicke des gebildeten Teiles der Nation auf die deutsche Kultur- und Geistesgeschichte. Die wichtigsten Männer in diesem FrozeB waren die Brüder Grimm. Sie waren sich eines nationalen Antriebs und $Z$ weckes ihres wissenschaftlichen Tuns wohl bewuBt. Ihr Streben nach nationaler Einheit und nach Sammlung und Beschreibung der deutschen geistigen Schätze war progressiv und völlig im Einklang mit der Zeit. Sie und andere begründeten die Germanistik.

Doch hatte die Germanistik einige Geburtsfehler. Die mangelnde Unterscheidung $\mathrm{zwischen}$ dem aus der Antike übernommenen Begriff der "germani" und dem Begriff der germanisch sprechenden Stämme Mitteleuropss um die Zeit Christi wies den Sprachgermanen einen größeren Geschichtsraum zu, als sie ihn wahrscheinlich besessen haben. Das konnte vom Nationalismus, wie hier ein übersteigertes Nationalbewußtsein genannt werden soll, ausgenutzt werden.

Eine mangelhafte Unterscheidung zwischen den Begriffen "deutsch" und "germınisch" verschaffte dem Deutschen ebenfalls eine größere Extension. Sie hatte in Deutschland Tradition, wurde aber durch die Autorität Jacob Grimms neu gestärkt, der sich weigerte, den "fremden Namen" germazisch zu benutzen, und diutisk, also deutsch für die Bezeichnung der germanischen Sprachen vorzog, was dahin führte, daß er sämtliche germanischen Sprachen „deutsche Sprachen" nannte. Das Gotische ist ihm also eine deutsche Sprache, ebenso das Angelsächsische.

Wir sprechen hier über die nationalpolitische Bedeutung der Germanistik, man muß aber hinzufügen, daß in Deutschland auch die Indogermanistik eine nationalpolitische Rolle gespielt hat. Vielleicht ist Deutschland das einzige Land, in dem die Indogermanistik für nationalpolitische Propaganda ausgebeutet wurde. Die Wissenschaftler, vor allem Bopp, der Begründer, und die späteren Junggrammatiker, haben eine Leistung vollbracht, die man zu den größten Leistungen der abendländischen Wissenschaft rechnen kann. In ihren Schriften findet sich kein nationaler 
oder nationalistischer Anklang. Von diesen Wissenschaftlern hatte der deutsche Nationalismus nichts zu hoffen. Dennoch übernahm er aus der Indogermanistik einige Themen und machte sie seinen $Z_{w e c k e n}$ dienstbar.

Die Entdeckung der indoeuropäischen Sprachfamilie brachte das Germanische und damit auch das Deutsche in direkte Verwandtschaft mit den Sprachen weltgeschichtlich hochberühmter Völker, der Inder, der Griechen und der Römer. Also wurden die germanischen Völkerschaften, speziell natürlich die späteren Deutschen, in einem falschen Schluß über die Sprache als ein ebenso großes Kulturvolk hingestellt. Als dann im Laufe des Jahrhunderts auch noch Nordeuropa und Norddeutschland als Ausgangsort der indogermanischen Wanderungen postuliert wurden, behaupteten deutsche Nationalisten, einige der größten Kulturen der Weltgeschichte seien von deutschem Boden ausgegangen.

Der deutsche Nationalismus des 19. Jahrhunderts wurde jedoch weniger von der Indogermanistik gespeist als vielmehr von Traditionen, die vor ihnen da waren: Das war die gänzlich außerwissenschaftliche, bösartige Argumentation aus der Zeit der Befreiungskriege, die sich gegen die Franzosen richtete, deren Sprache als verdorben von ihren römischen Anfängen an hingestellt wurde. Diese Agitation war seit dem Barock bekannt, und ihre Neuauflage eröffnete ihrerseits neue Wege zu einem haBerfüllten Dilettantismus bis ins 20. Jahrhundert hinein. Sie ist heute erloschen.

Der immer aggressiver auftretende deutsche Nationalismus schöpfte noch aus einer dritten sprachlichen Quelle, der Sprachphilosophie Wilhelm von Humboldts. Diese ging auf universalistische und weltbürgerliche Gedanken des 19. Jahrhunderts zurück und war zunächst national gar nicht verwertbar. Aber einige Postulate erwiesen sich als brauchbar und als verhängnisvoll.

Erstens: Daß die Sprachen der Welt in aufsteigender Linie die geistige Entwicklung des Menschengeschlechts begleiteten, daß es also vollkommenere und weniger vollkommene Sprachen gäbe, und weiter, daß die indogermanischen Gektierenden Sprachen in der Werteskala der Sprachen den höchsten Rang einnähmen, was ein ethnozentrischer Irrtum war.

Zweitens: Daß die Sprachen der Nationen von einem Geist der Nationen aufgebaut seien, der an ihnen noch erkennbar sei, und daß jeder Nationalgeist vom anderen verschieden sei. Diese Gedanken fuhren in die Köpfe deutscher nationalistischer Fanatiker und brachten eine endlose Kette falscher Schlüsse über den deutschen Nationalcharakter und den Geist 
der deutschen Sprache hervor. Auch diese Tradition, die kein einziges wissenschaftliches Ergebnis hervorgebracht hat, ist heute erloschen.

Zum Schluß möchte ich eine Kuriosität anführen: Bei der Erörterung der nationalpolitischen Bedeutung der Germanistik muß man fragen, wer die Leute waren, die mit Sammlungen von Sprach- und Textzeugnissen das deutsche Nationalbewußtsein wecken wollten: Es waren die sprachwissenschaftlich Gebildeten aus den höheren Mittelschichten. Und wer die Leute waren, die mit falscher Berufung auf sprachliche Tatsachen den deutschen Nationalismus anfeuerten: Das waren die sprachwissenschaftlich weniger Gebildeten, die aber der gleichen sozialen Schicht angehörten. Diese Schicht nennt man heute Intelligenz. Die Unterklassen, die Bauern und das sich herausbildende Proletariat, waren zu Sprachreflexionen überhaupt nicht imstande, konnten wohl nicht einmal ein Fremdwort als solches identifizieren. Heute, nach hundert und mehr Jahren, ist die Lage gerade umgekehrt: Der größte Teil der Intelligenz ist anational, wenn nicht sogar antinational, und das sogenannte Volk ist national gesinnt. Bei beiden Teilen der Nation gibt es allerdings kaum noch Berufungen auf die Sprache.

\section{Beiträge der Zuhörer}

Staat, Sprache und Nation stimmen in der Neuzeit mit Ausnahme von Island nirgends überein.

Gründe für die Fremdwortfeindschaft in Deutschland scheinen zu sein:

1. daß die Oberschicht in Deutschland eine französische Sprachkultur gepflegt hat,

2. die Stimmung gegen Napoleon,

3. die Irrealität des Heiligen Römischen Reiches.

Der Anspruch auf die älteste Sprache hing mit einer deutschen Identitätsschwäche zusammen, war angstgespeist und entsprang nicht einem souveränen Überlegenheitsgefühl. 